
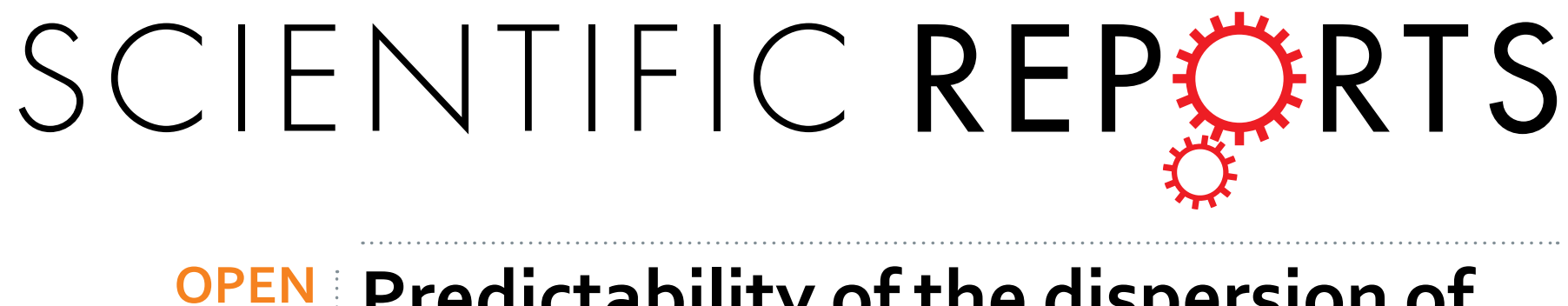

\title{
Predictability of the dispersion of Fukushima-derived radionuclides and their homogenization in the
}

Received: 29 July 2015

Accepted: 09 December 2015

Published: 28 January 2016 atmosphere

\author{
Róbert Mészáros ${ }^{1}$, Ádám Leelössy ${ }^{1}$, Tibor Kovács² \& István Lagzi ${ }^{3}$
}

Long-range simulation of the dispersion of air pollutants in the atmosphere is one of the most challenging tasks in geosciences. Application of precise and fast numerical models in risk management and decision support can save human lives and can diminish consequences of an accidental release. Disaster at Fukushima Daiichi nuclear power plant has been the most serious event in the nuclear technology and industry in the recent years. We present and discuss the results of the numerical simulations on dispersion of Fukushima-derived particulate ${ }^{131}$ I and ${ }^{137} \mathrm{Cs}$ using a global scale Lagrangian particle model. We compare concentrations and arrival times, using two emission scenarios, with the measured data obtained from 182 monitoring stations located all over the Northern Hemisphere. We also investigate the homogenization of isotopes in the atmosphere. Peak concentrations were predicted with typical accuracy of one order of magnitude showing a general underestimation in the case of ${ }^{131} \mathrm{I}$ but not for ${ }^{137} \mathrm{Cs}$. Tropical and Arctic plumes, as well as the early detections in American and European midlatitudes were generally well predicted, however, the later regional-scale mixing could not be captured by the model. Our investigation highlights the importance of the parameterization of free atmospheric turbulence.

The Fukushima Daiichi nuclear disaster has been the second most serious crisis of a nuclear power plant in the human history. The release period lasted over two months emitting a significant amount of radioiodine, radioxenon and radiocaesium as well as other isotopes such as plutonium ${ }^{1,2}$. Besides the local to regional scale impacts of soil and water pollution, isotopes released into the atmosphere could be measured globally ${ }^{3}$. Total atmospheric release was estimated to be $14000-15300 \mathrm{PBq}$ of radioxenon and $340-800 \mathrm{PBq}$ of other isotopes ${ }^{4}$. The radioactive plume in the atmosphere moved towards the Pacific, reached North America in five days and Europe in eight days, and returned over Japan around the Northern Hemisphere within only 20 days. Although health concerns have not arisen out of Japan, Fukushima-derived radioiodine and radiocaesium could be identified in the entire Northern Hemisphere as a tracer of atmospheric dispersion. Measurements were made at several sites by international and national monitoring networks as well as research groups and expedition campaigns ${ }^{3}$. The large number of data points allows the identification of transport pathways as well as the evaluation of dispersion model performance and emission scenarios.

While monitoring stations provided valuable data for concentrations in the atmosphere, the emission term and its temporal variability was not known during the accident ${ }^{5}$. The emission was caused by several different processes, including two hydrogen explosions, controlled release and uncontrolled emission for several weeks. Initial estimates of total ${ }^{131}$ I release into the atmosphere ranged from 150 to $500 \mathrm{PBq}^{1}$. Modelling efforts focused on inverse methods that provided more accurate estimates of $65-400 \mathrm{PBq}$ for total ${ }^{131} \mathrm{I}^{1,6}$. Among others, the WSPEEDI (Worldwide System for Prediction of Environmental Emergency Dose Information) model has been used with data obtained from the Japanese measurement network to estimate a more detailed emission inventory and emission rates, resulting in a total ${ }^{131} \mathrm{I}$ emission of $124 \mathrm{PBq}$ and ${ }^{137} \mathrm{Cs}$ emission of $8.8 \mathrm{PBq}^{7}$. Recently, the improved WSPEEDI-II model has provided an updated emission data and a detailed reconstruction of the events

${ }^{1}$ Department of Meteorology, Eötvös Loránd University, Budapest, Hungary. ${ }^{2}$ Institute of Radiochemistry and Radioecology, University of Pannonia, Veszprém, Hungary. ${ }^{3}$ Department of Physics, Budapest University of Technology and Economics, Budapest, Hungary. Correspondence and requests for materials should be addressed to R.M. (email:mrobi@nimbus.elte.hu) 

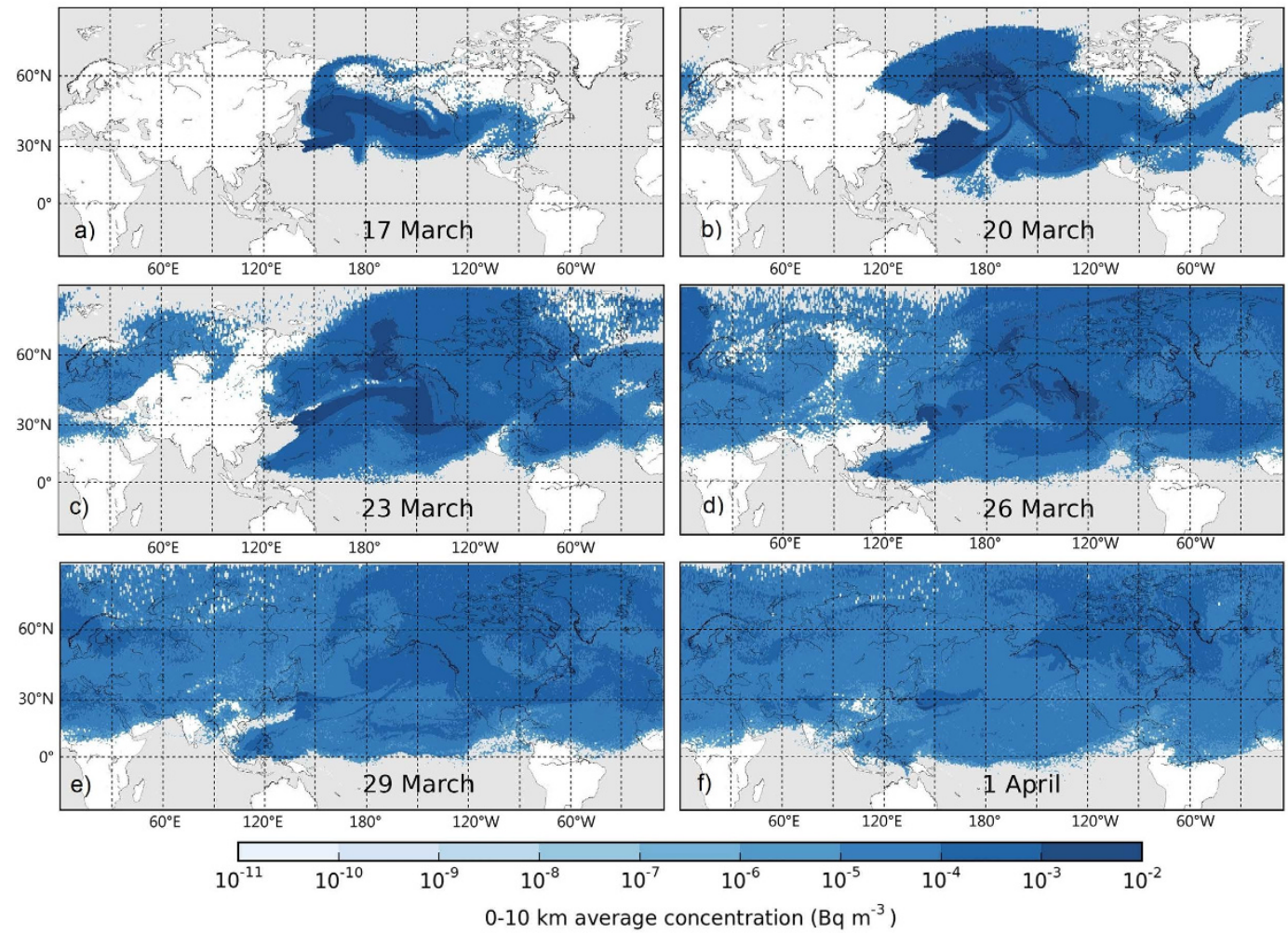

Figure 1. Modelled ${ }^{131}$ I activity concentrations in the troposphere $(0-10,000 \mathrm{~m})$ on the $6^{\text {th }}, 9^{\text {th }} 12^{\text {th }}, 15^{\text {th }}, 18^{\text {th }}$ and $21^{\text {st }}$ days after the initial release. The figure was made with the Matplotlib Basemap package ${ }^{60}$.

leading to the accidental release ${ }^{8}$. This latest work concluded a total of $150 \mathrm{PBq}^{131} \mathrm{I}$ and $14.4 \mathrm{PBq}{ }^{137} \mathrm{Cs}$ emission. Besides the increased total emission compared to the previous estimation, the results of WSPEEDI-II yielded an improved timeline for the first hydrogen explosion and the emission peak on the night 14-15 $\mathrm{March}^{8}$.

Here we present a study using a Lagrangian model to evaluate the predictability of the transport of the radioactive plume across the globe comparing modelled concentration values and arrival times to the measured data. We also investigate the improvement of modelled results provided by the WSPEEDI-II emission data compared to earlier reported WSPEEDI emission data. Additionally, based on geographical locations and arrival times we could group the measurement sites into clusters corresponding to different atmospheric transport pathways (Supplementary Figure S1). It should be noted that we focused on dispersion on global scale, therefore, sites within Japan were not investigated in this study.

\section{Results}

Rapid eastward transport by the jet stream. The most important factor in prediction of the global dispersion of Fukushima-derived isotopes was the location of the jet stream. Jet stream is a high tropospheric flow at midlatitudes with mean zonal (westerly) velocities reaching $100 \mathrm{~m} \mathrm{~s}^{-1}$. Cyclones and frontal systems are closely related to meridional (north-south) waves of the jet stream that can reach amplitudes of 1000-3000 kilometres. The pollution cloud was initially captured by an extratropical cyclone over the Western Pacific during the first few days of the release period causing most of the radioactive fallout occurring to the northeast of Japan ${ }^{3,6,9,10}$. The plume was lifted to the middle and high troposphere and, therefore, it was rapidly transported northeastward, arriving to North America only within 5-6 days (Fig. 1 and Supplementary Movie S1) ${ }^{3,4,6,11}$. Strong wind shear in frontal systems over the Eastern Pacific split the plume into two parts: one reaching Alaska and the Canadian Arctic, while the other arriving at the USA West Coast on 16-18 $\mathrm{March}^{3,6,11}$ (Fig. 1a and Supplementary Figure S2). Although the fast transport of pollutants occurred in the strong middle and high tropospheric winds, frontal systems following the jet stream caused efficient vertical mixing that allowed early detection of radioiodine in the planetary boundary layer $(\mathrm{PBL})^{11}$. Vertical turbulence related to frontal systems and deep convection provided efficient vertical mixing in both directions: it was responsible for the initial rapid lifting of the plume as well as the later downward transport to the atmospheric boundary layer (Supplementary Figure S3 and Supplementary Movie S2) ${ }^{12}$.

Arrival of the plume was detected on the same day (17 March) at multiple sites in British Columbia, Washington and California ${ }^{3,11,13}$. By this time, the plume had reached the high troposphere and was transported eastward in a narrow band by high tropospheric zonal winds reaching velocities of $50-70 \mathrm{~m} \mathrm{~s}^{-1}$ over the Northern Atlantic $^{3,14}$ (Fig. 1b and Supplementary Movie S2). Vertical mixing was still provided by frontal convection and precipitation attached to the jet stream, thus Fukushima-derived radioiodine was detected early on the surface following the jet stream pathway in New York State $(18 \mathrm{March})^{15}$, Iceland and Norway $(19-20 \mathrm{March})^{16}$, Sweden, 
Finland and Western Russia (21-22 March) ${ }^{17,18}$ (Supplementary Figures S2 and S3). Over Asia, the jet stream formed meridional waves resulting in a slower and more heterogeneous transport of radioiodine over Asia with arrival to South Korea on $28 \mathrm{March}^{19}$, Taiwan on $29 \mathrm{March}^{20}$ and China only on $31 \mathrm{March}^{21}$. Initial jet stream transport to North America and Europe occurred in the typical height of the jet core $(8-10 \mathrm{~km})$ followed by slower and denser low and middle tropospheric plumes. Therefore, concentration peaks occurred several days after the arrival time with values ranging $1.2-14 \mathrm{mBq} \mathrm{m}^{-3}$ in North America, $0.6-3.8 \mathrm{mBq} \mathrm{m}^{-3}$ in Northern Europe and $0.1-8 \mathrm{mBq} \mathrm{m}^{-3}$ in Asia for particulate ${ }^{131} \mathrm{I}^{3}$.

Alaska and the Canadian Arctic. After the initial plume from Fukushima had split into two parts over the Western Pacific, the northern arm reached the Arctic at approximately the same time as the southern arm arrived at the West Coast ${ }^{11}$. The first detection was reported from the Aleutian Islands on $17 \mathrm{March}^{22}$, however, further intrusion to the Arctic was temporarily blocked by a high pressure system. A developing polar cyclone captured the plume and transported northward with arrival times 18-21 March in Alaska and 21-23 March in the Canadian Arctic ${ }^{3,13,22}$ (Fig. 1c and Supplementary Figure S2). Peak concentrations were in the range of $2.9-25.5 \mathrm{mBq} \mathrm{m}^{-3}$ for particulate ${ }^{131} \mathrm{I}^{3,13,22}$. The plume was further transported through the Arctic to Svalbard and Northern Europe $\mathrm{e}^{23,24}$.

Regional dispersion over North America. The zonal jet stream transported the plume across North America within one day in a narrow band over the Northern USA. This line as well as further Fukushima-derived plumes arriving at the West Coast were the initial state of the regional dispersion dominated by low and middle tropospheric winds. Early detections were reported between 17 and 19 March from three stations in Central and Southern USA: Ashland, KS, Chapel Hill, NC and Melbourne, FL ${ }^{3,22,25}$. Kansas and North Carolina were reached by a fast moving cold front at the detection time, however, Florida was dominated by a subtropical high pressure system until 21 March. The plume arrived to Orlando, FL, located in a distance of $100 \mathrm{~km}$ from Melbourne, FL, only on 25 March with a much lower peak concentration ${ }^{3}$. Other North American stations reported arrival times between 20 and 25 March except those located at the zonal jet stream path. During this period, the homogenization was driven by fast moving low pressure systems with strong horizontal and vertical turbulence as well as precipitation. These effects resulted in fast transport and dilution of the pollutants with arrival times ranging only 5 days but peak concentrations between 0.44 and $31.08 \mathrm{mBq} \mathrm{m}^{-3}$ for particulate ${ }^{131} \mathrm{I}^{3}$.

Regional dispersion over Europe. The large number of European measurement sites provided a fine spatial resolution of data from which European dispersion patterns have been identified ${ }^{17}$. The plume was transported to Europe by the zonal jet stream through the North Atlantic and arrived to Scandinavia on 20-22 March (Fig. 1 and Supplementary Figure S2). At this time, a strong high pressure system was blocking Western and Central Europe with sea level pressures exceeding $1030 \mathrm{hPa}$ on a large area from England to Western Russia. Regional transport over Europe occurred within this high pressure system that remained stable until 25-26 March. Following the anticyclonic flow, the first observations and highest peak concentrations were reported in Northern and Eastern Europe with arrival times 21-24 March through Belgium, Germany, Denmark, Belarus, Poland and the Carpathian Basin ${ }^{17,26-31}$. By 23-26 March, the plume had been detected in entire Europe except in Southern Italy where a subtropical high pressure system blocked the dispersion until 27-30 $\mathrm{March}^{24,27,32-49}$. During this time, another transport pathway was also playing role from the Pacific through the high Arctic that reached Svalbard on 25 March and merged with zonally transported plumes over Northern Europe ${ }^{23,24}$. As regional transport over Europe was dominated by weak anticyclonic winds with no significant precipitation and inefficient vertical mixing, detection times and concentrations were highly dependent on local weather thus showed strong spatial and temporal variability. The homogenization over Europe was slow and heterogeneous with arrival times ranging 10 days and peak concentrations between 0.2 and $9.6 \mathrm{mBq} \mathrm{m}^{-3}$ for particulate ${ }^{131} \mathrm{I}$, often with multi-peak concentration time series ${ }^{3,17,29}$.

Tropical Central Pacific. Despite their relative vicinity to Japan, the Pacific islands of Guam and Wake Island remained intact for the first week of the accident as the initial plume was captured by an extratropical cyclone and transported northeastward. The Hadley cell was penetrated by frontal systems over the Central and Western Pacific on 16-18 $\mathrm{March}^{3}$. Isotopes were transported eastward by trade winds and merged with later emitted plumes penetrating the Hadley cell by multiple frontal zones. Tropical convection provided efficient vertical mixing, thus relatively high surface concentrations $\left(2.3-24.4 \mathrm{mBq} \mathrm{m}^{-3}\right)$ were detected with arrival times $19-21$ March on Wake Island, Hawaii, Guam and the Northern Mariana Islands ${ }^{3,22}$.

Tropical Western Pacific. Huh et al. (2012) pointed out an important transport pathway from Fukushima to Southeastern Asia between 17 and $24 \mathrm{March}^{20}$. With the emission still being significant, a strong frontal system over Japan transported the isotopes in southwestern direction penetrating the Hadley cell over the Western Pacific. The plume was transported in the boundary layer by trade winds and was detected in Manila $(23 \mathrm{March})^{3}$, Taiwan $(25 \mathrm{March})^{20}$, Hongkong and Vietnam (27 March) ${ }^{50}$. Taiwan was also reached by a high tropospheric plume via global jet stream transport on 29 March (Fig. 1e and Supplementary Figure S2) ${ }^{20}$.

Dispersion over Asia. Due to their vicinity to Japan, measurements were carried out at several sites in China and South Korea. However, no direct eastward transport was detected from Fukushima, and the area was first reached by the high tropospheric plume transported around the globe. The first detection was reported at all 12 South Korean stations on 28 March and at all 24 Chinese stations on 31 March - 1 April ${ }^{3,19}$.

A cyclonic system reached South Korea on 28 March causing downward mixing directly from the global jet stream transport. The later detections in China can be explained with a ridge causing mean sea level pressures exceeding $1030 \mathrm{hPa}$ blocking the plume for several days. 


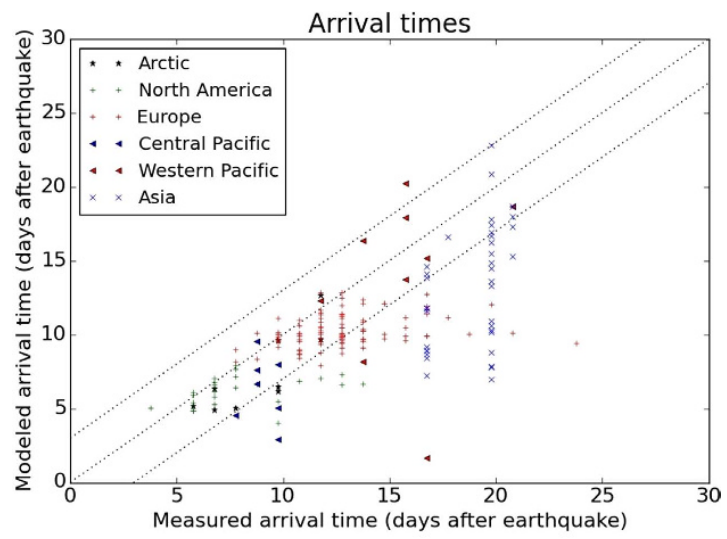

Figure 2. Comparison of measured and modelled arrival times for particulate ${ }^{131} \mathrm{I}$ and ${ }^{137} \mathrm{Cs}$.
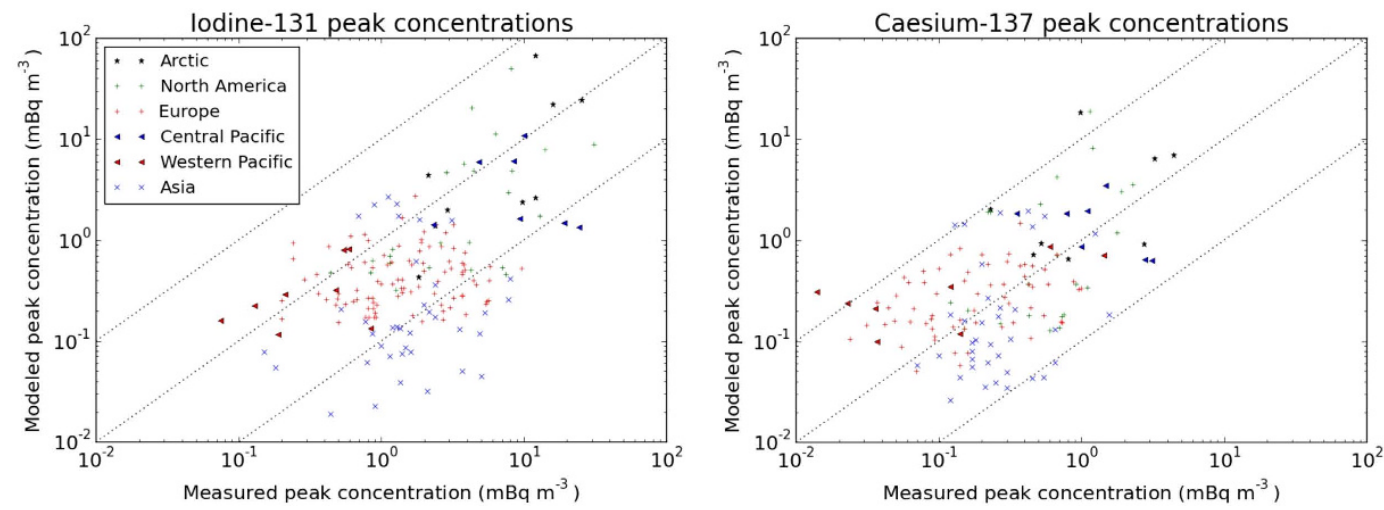

Figure 3. Comparison of measured and modelled peak daily average concentrations for particulate ${ }^{131}$ I and ${ }^{137} \mathrm{Cs}$.

\begin{tabular}{|c|c|c|c|c|c|c|c|}
\hline \multirow[b]{2}{*}{ Region } & \multirow[b]{2}{*}{$\begin{array}{c}\text { Number of } \\
\text { measurement sites } \\
\left({ }^{131} \mathrm{I} /{ }^{137} \mathrm{Cs}\right)\end{array}$} & \multicolumn{3}{|c|}{ Aerosol ${ }^{131} I$} & \multicolumn{3}{|c|}{ Aerosol ${ }^{137} \mathrm{Cs}$} \\
\hline & & 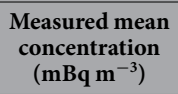 & $\operatorname{RMSE}\left(\mathbf{m B q} \mathbf{m}^{-3}\right)$ & $\mathrm{CV}$ & 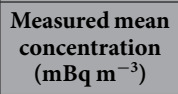 & $\begin{array}{c}\text { RMSE } \\
\left(\mathrm{mBq}^{-3}\right)\end{array}$ & $\mathrm{CV}$ \\
\hline Arctic & $8 / 8$ & 9.4 & 4.9 & 0.5 & 1.7 & 1.8 & 1.1 \\
\hline North America & $23 / 22$ & 5.8 & 6.9 & 1.2 & 0.77 & 1.9 & 2.5 \\
\hline Europe & $95 / 64$ & 2.0 & 2.2 & 1.1 & 0.26 & 0.31 & 1.2 \\
\hline Asia & $37 / 37$ & 2.1 & 2.6 & 1.3 & 0.33 & 0.62 & 1.9 \\
\hline Central Pacific & $7 / 7$ & 11.2 & 11.4 & 1.0 & 1.5 & 1.6 & 1.1 \\
\hline Western Pacific & $8 / 8$ & 0.38 & 0.29 & 0.76 & 0.30 & 0.32 & 1.1 \\
\hline
\end{tabular}

Table 1. Comparison of modelled peak concentrations to measurements in each region.

Global arrival times and peak concentrations. Concentrations were simulated with a Lagrangian trajectory model for the first 35 days of the release (Fig. 1 and Supplementary Figure S2). Arrival times representing both iodine and caesium and peak daily concentrations for each isotope are shown in Figures 2 and 3. Intercontinental transport occurred mostly in the middle and high troposphere and main dispersion patterns were well predictable in the free atmosphere. However, vertical mixing from the high troposphere to the planetary boundary layer largely depended on the more uncertain processes of meso-scale turbulence ${ }^{12,51}$, frontal zones, convection and precipitation. Planetary boundary layer transport also played a significant role in the Western Pacific $^{20}$. The plume location was mostly well predicted and surface arrival times had an uncertainty of a few days with mean absolute error (MAE) of 2.8 days (Fig. 2). Modelled ${ }^{131} \mathrm{I}$ peak concentrations were within the range of one order of magnitude to the measurements (Fig. 3). Values for root mean squared error (RMSE) and coefficient of variation (CV, RMSE divided by the mean of the measured values) at each region are given in Table 1 . This level of uncertainty is comparable to that of other model results ${ }^{6,8,14,52}$. 

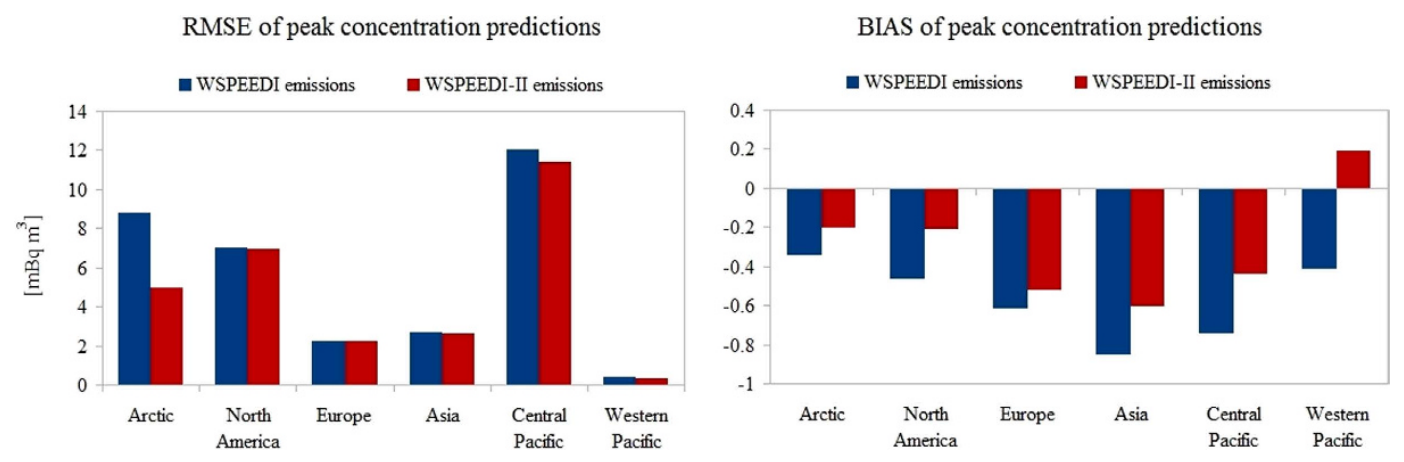

Figure 4. Improvement of global peak particulate ${ }^{131}$ I concentration predictions by updated emission inventory compared to earlier emission estimates ${ }^{7,8}$.

Measurement data points were split into six regions as described previously (Figs 2 and 3). The initial rapid global transport by the jet stream was well predicted by the model with mean absolute error of 2.4 and 2.7 days for arrival times at North American and European stations, respectively. This uncertainty is comparable to the temporal variance of arrival time among stations.

Peak concentrations of ${ }^{131}$ I were predicted with similar uncertainty along the zonal transport pathway through North America, Europe and Asia. However, the negative values of the mean relative error (BIAS) showed an overall underestimation of peak ${ }^{131}$ I concentrations (Fig. 4). Peak concentrations of ${ }^{137}$ Cs do not show this general underprediction and have a smaller RMSE, however, the relative error is generally larger.

The large regional variability of peak concentrations within the USA was captured, and model results remained in the same order of magnitude with measurements with the exception of two extremely large peaks in Utah and Indiana. Although the plume arrival times at Arctic stations were similar to those of North America, predictability in the Arctic was better.

In Europe, mixing occurred under anticyclonic conditions. High tropospheric transport of the plume through the Northern Atlantic was captured by the model and early surface detections were well predicted in Iceland and Scandinavia. The general transport and magnitude of the plume were well modelled over Europe, however, the large regional and local variability of concentrations caused worse prediction of the latest arrivals and the largest peaks. In the Tropical Pacific regions, peak concentrations were generally better predicted than those of extratropical latitudes. Arrival times were generally well predicted, however, a few early predictions were related to false locations of westward moving plumes in Southeast Asia.

Comparison of emission scenarios. The latest emission estimate of Katata et al. ${ }^{8}$ (WSPEEDI-II) was compared to their earlier results ${ }^{7}$ (WSPEEDI) to demonstrate the sensitivity of global results on the improved local scale deposition scheme used in WSPEEDI-II. Peak ${ }^{131}$ I concentration results improved in all regions as the larger total emission of WSPEEDI-II reduced the general underestimation of concentrations (Fig. 4). The largest improvement was observable in the Arctic, while other regions showed only a minor change in RMSE but a significantly better BIAS. Similar improvement was not found in case of ${ }^{137} \mathrm{Cs}$, where the increased total amount of the release resulted in a general overestimation of peak concentrations (Supplementary Figure S4).

Large difference between the two emission scenarios was observable in Southeast Asia. Using the WSPEEDI-II emission data, several days of improvement of arrival time predictions was achieved in case of Manila (Philippines), Dalat (Vietnam) and Hongkong (China). This supports the corrected estimation of the 15 March emission by WSPEEDI-II ${ }^{8}$ as this release period corresponded to the boundary layer transport towards Southeast Asia $^{20}$. General accuracy of peak concentrations has also largely improved in this region (CV from 0.92 to 0.76 in case of ${ }^{131} \mathrm{I}$; and from 1.58 to 1.07 in case of ${ }^{137} \mathrm{Cs}$ ), while the positive BIAS was due to the overprediction of peak concentrations in Vietnam in the WSPEEDI-II scenario.

Hemispheric homogenization. The very long duration of the emission from Fukushima was comparable to meridional homogenization time (Fig. 5). Zonal and meridional total activities were integrated one month after the earthquake with 5 degree zonal and 10 degree meridional resolution (Fig. 6). Although hemispheric homogenization did not apply as zonal total activities showed a defined peak at midlatitudes, the region between 40 and $60^{\circ} \mathrm{N}$ was already well mixed holding $34 \%$ of total global atmospheric activity of ${ }^{131} \mathrm{I}$. The tropical regions were dominated by the Hadley cell, a stable and relatively closed circulation pattern that is only rarely penetrated by extratropical cyclones. Southward transport was blocked by tropical high pressure regions and the intertropical convergence zone. Therefore, only $1.3 \%$ of the global ${ }^{131} \mathrm{I}$ activity was over the Southern Hemisphere at the end of the first month (Figs 5 and 6). A significant intrusion to the southern tropics can be observed towards Australia and the Southwestern Pacific in Fig. 6. After the first month of the dispersion, $16 \%$ of the atmospheric ${ }^{131}$ I activity was over tropical latitudes and $20 \%$ in northern Polar Regions. The northward gradient of concentration can be explained by the fact that the atmospheric lifetime of ${ }^{131} \mathrm{I}$ is shorter in tropical regions due to efficient wet deposition processes. 


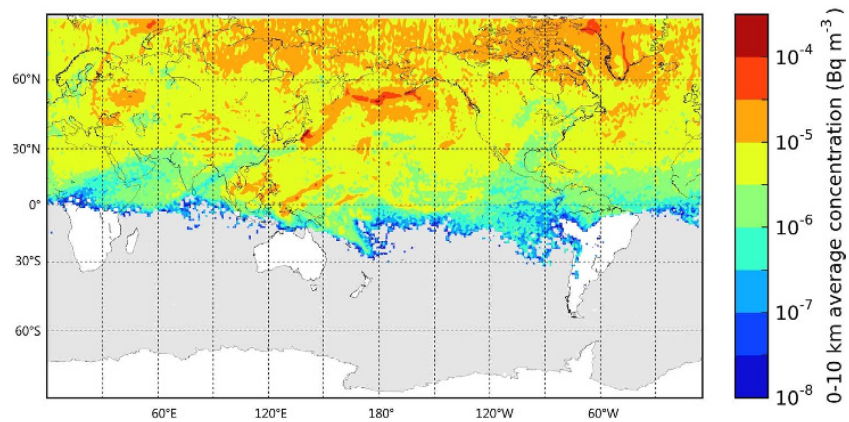

Figure 5. Simulated average tropospheric $(0-10 \mathrm{~km})$ particulate ${ }^{131} I$ activity concentration on $11^{\text {th }}$ of April after 31 days of the earthquake. The figure was made with the Matplotlib Basemap package ${ }^{60}$.
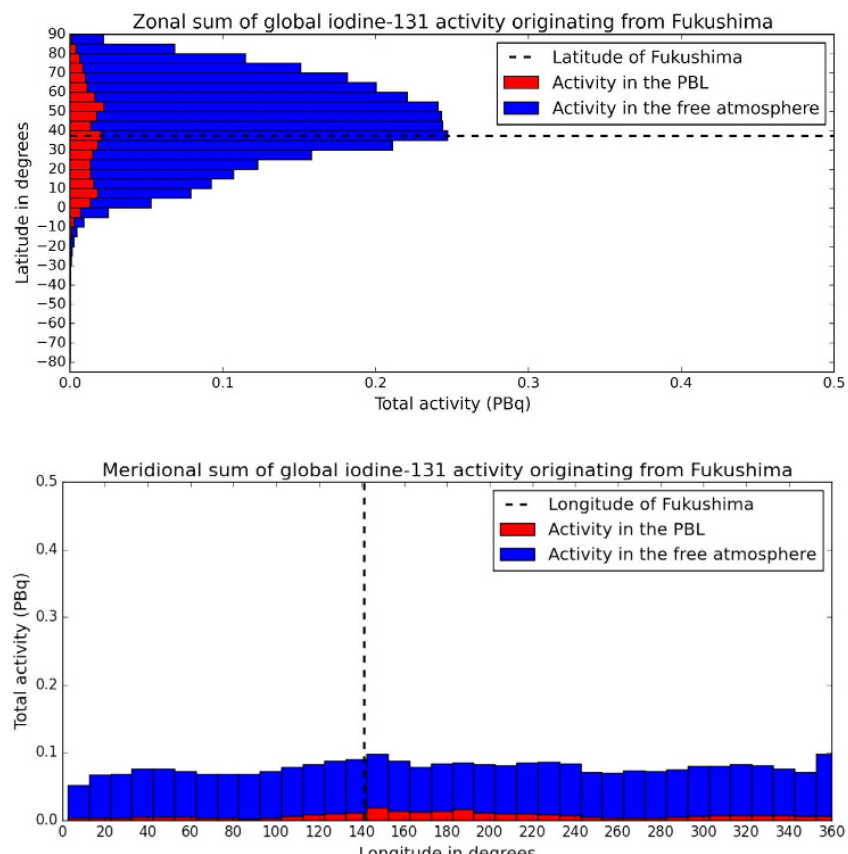

Figure 6. Zonal and meridional homogenization of particulate ${ }^{131} \mathrm{I}$ in the atmosphere on $11^{\text {th }}$ of April after 31 days of the earthquake.

\section{Discussion}

Predictability of the arrival time of the plume was different among regions, and depended largely on the complexity of the atmospheric circulation systems governing the dispersion. The best correlations can be observed in the tropical and Arctic regions due to the relatively stable trade and polar winds. In American and European midlatitudes, the early detections were generally well predicted by the model, however, the later regional-scale mixing could not be captured, significantly underestimating the arrival times at several sites.

It should be noted that concentration patterns and model performance was studied for a limited number of measurement sites and therefore may not be representative for entire regions. The density of measurement network was fine in Europe, North America and Eastern-Southeastern Asia, however, much coarser in Pacific and Arctic regions. Therefore, measurements in the latter regions are less representative for the absolute peak concentration and predictability of the entire area. The number of measurement sites by region is shown in Table 1.

In Asia, there is a contradiction in the westward moving plumes between 20 and 28 March. Reported measurements in South Korea and China suggest that the first detections were caused by the global hemispheric transport on 28-31 March $^{3,19,53}$. This arrival time of the high tropospheric plume is supported by our model, however, model results showed earlier surface detections in South Korea between 21 and 26 March and a slow mixing over China between 21 and 31 March due to westward transport from Fukushima (Fig. 1 and Supplementary Fig. 2). It has been shown in previous model simulations that an anticyclonic system forced the plume to northwestward direction between 20 and 24 March that could marginally reach Northeastern China and the Korean Peninsula ${ }^{3,6,20}$. Our model also suggests further westward dispersion to mainland China by 26 March. However, this early transport was not supported by other model and measurement results ${ }^{3,14,19,53}$. Contrary to these, 


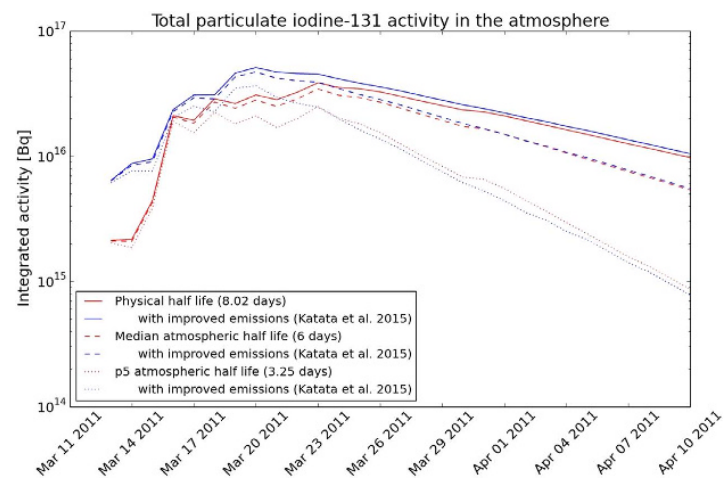

Figure 7. Comparison of total atmospheric activity of particulate ${ }^{131}$ I with initial ${ }^{7}$ and improved ${ }^{8}$ emission scenarios. Decay rates among the physical half-life of 8 days and reported median and $5 \%$ percentile (p5) atmospheric half life of 6 and 3.25 days $^{29}$, respectively, are compared.

detection of Fukushima-derived radionuclides was reported from a study in Xi'an, Central-Eastern China on 23 March with a significant peak on $25 \mathrm{March}^{54}$, more according to our estimates. To assess this contradiction, we also used results from the online version of HYSPLIT (Hybrid Single Particle Lagrangian Integrated Trajectory Model) applied for the Fukushima case using the Transfer Coefficient Matrix (TCM) method ${ }^{52}$. The concentration timeline for Xi'an and Seoul provided by HYSPLIT radically supported the scenario of a significant westward transport with arrival times as early as 15-16 March in Xi'an and Seoul. HYSPLIT also showed the reported peak in Xian on 25 March. The high uncertainty of the pathway and surface detectability of early westward moving plumes from Fukushima points out the importance of further studies.

The initial ratio of gaseous to total ${ }^{131}$ I was obtained from the emission scenario ${ }^{8}$, however, this ratio was decreased by wet scavenging of aerosols throughout the dispersion. Wet scavenging of ${ }^{131} \mathrm{I}$ is one of the most uncertain processes of atmospheric dispersion that is highly dependent on the ratio of the chemical forms of iodine in the plume as well as precipitation and cloud data obtained from global meteorological models. Despite neglecting all sink processes except radioactive decay and wet scavenging, our results showed an overall underprediction of ${ }^{131} \mathrm{I}$ peak concentrations, a similar phenomena that had been assessed in previous modelling studies $^{14,52}$.

Initial gaseous/total ratio was measured between 30 and $67 \%$ in $\operatorname{Japan}^{55}$ and 40 and $100 \%$ in Europe and North America ${ }^{3}$. Wet scavenging was shown to decrease the contribution of particle form to the total, therefore largest gaseous/total ratios were measured at locations where transport was permanently accompanied with precipitation, mostly related to the jet stream ${ }^{3}$. The development of WSPEEDI-II for the latest emission estimate focused largely on the representation of different deposition processes for gaseous and particulate iodine ${ }^{8}$. They assumed $50 \%$ gaseous/total ratio for the initial, largest emissions and an integrated ratio of $54 \%$ for the entire release $^{8}$. Based on measurements in North America and Europe, an average atmospheric ratio of $76.7 \pm 12 \%$ was calculated for the period until $22 \mathrm{April}^{3}$. This yields an average uncertainty of concentrations with a factor of 1.5 due to wet scavenging which is comparable to the uncertainty of the initial ratio of aerosol and gas forms. Atmospheric half-life of particulate ${ }^{131}$ I was estimated to be 6 days (median) with a range between 3.25 and 8.5 days ${ }^{28,29}$. Figure 7 clearly shows that the uncertainties caused by deposition processes dominate over uncertainties of emission scenarios only after 20-25 March.

It has been shown previously that in atmospheric dispersion problems, exchange of pollutants between the planetary boundary layer and the free atmosphere plays a significant role ${ }^{56}$. On regional to global scales, downward convective vertical transport can contribute significantly to surface concentrations ${ }^{12}$. These effects are often poorly represented in dispersion models. In this study, we applied constant diffusion coefficients above the planetary boundary layer. However, we performed model runs using various scenarios for turbulent mixing in the free atmosphere, and our study revealed that improper parameterization of the free atmospheric turbulence give rise to errors greater than one order of magnitude in the prediction of surface concentrations. Parameterization of turbulent processes in the free atmosphere would provide new directions for further studies in air quality modelling.

\section{Methods}

In this study we used the RAPTOR dispersion model for the simulation of arrival times and ${ }^{131}$ I activity concentrations in the atmosphere for a 35-day period. This continental/global scale trajectory model was developed at the Eötvös Loránd University, Hungary. Four million particles were emitted and their trajectories were calculated for the entire simulation time. Each particle represented a fraction of the total activity that decreased with radioactive decay and wet deposition over time. The model used longitude-latitude horizontal and $z$ (absolute) vertical coordinates. Digital elevation data from the Global Land One-km Base Elevation Project ${ }^{57}$ was used to provide more accurate results of plumes traversing complex terrain. Particles were moved along air parcel trajectories determined by the sum of the grid-scale wind and the subgrid-scale stochastic turbulent velocity, solving the ordinary differential equation with a simple first-order forward scheme. The turbulent velocities were calculated using the Langevin equation with turbulent parameters obtained from Hanna's parameterization ${ }^{51,58}$. Atmospheric stability was characterized with the Monin-Obukhov-length calculated directly from heat flux data provided by the meteorological model. Aerosol wet scavenging was parameterized with a simple first-order deposition scheme 
assuming the same size distribution for both iodine and caesium aerosols. Scavenging coefficients were calculated separately from large-scale and convective precipitation rates using empirical parameters given by Leadbetter et al. $(2015)^{59}$.

To save computational time, only the two major sink processes: radioactive decay and wet scavenging were taken into account. The incorporation of surface dry deposition requires land use data and surface-atmosphere interaction parameterizations that largely increase the computational cost and the amount of data involved. This increase in computational cost is not proportionate to the improvement of concentration results, having uncertainty of one order of magnitude compared to measurements. One could use a constant dry deposition velocity, however, this would not take into account the spatial and temporal variability of dry deposition (as it is taken into account in the case of wet scavenging through precipitation intensity). It is more justifiable to introduce a slight general underestimation by neglecting the dry deposition than a slight bias in time- and space-dependent direction by defining a constant dry deposition velocity.

Input meteorological data was obtained from the Global Forecast System (GFS, http://www.emc.ncep.noaa. gov) with horizontal resolution of 0.5 degree. To maximize meteorological data accuracy with keeping the 3 hourly temporal resolution, we used the 3 and 6 hour forecast files of consecutive GFS runs. Three-dimensional fields and model vertical velocities were interpolated from pressure to absolute height levels. GFS provides 3D wind field for the trajectory simulation, while 2D meteorological data (height of the planetary boundary layer, heat fluxes, surface wind speed and temperature) were used to estimate the Monin-Obukhov-length and the turbulent velocities. Concentrations were calculated from trajectory positions every hour on the grid of the input meteorological data with 0.5 degree resolution. Model concentration outputs were averaged for 24 hours for comparison with measurement data from 24-hour samples ${ }^{29}$. The model was implemented in the Anaconda Python framework ${ }^{60}$.

Measurement data was mostly obtained from the review of Thakur et al. ${ }^{3}$ who published data for several CTBTO (Comprehensive Nuclear-Test-Ban Treaty Organization) sites as well as observations from national networks and research institutions. Besides referenced publications and the CTBTO, original data sources had been the US Environmental Protection Agency, the University of California, the Washington State Department of Health, national radiation safety authorities and public research centres of European countries and the Ministry of Environmental Protection of China. Emission data (emission rate and amount) was obtained from Katata et al. ${ }^{8}$ and their earlier work ${ }^{7}$.

\section{References}

1. Lin, W. et al. Radioactivity impacts of the Fukushima Nuclear Accident on the atmosphere. Atmos. Environ. 102, 311-322 (2015).

2. Zheng, J. et al. Isotopic evidence of plutonium release into the environment from the Fukushima DNPP accident. Sci. Rep. 2, doi: 10.1038/srep00304 (2012).

3. Thakur, P., Ballard, S. \& Nelson, R. An overview of Fukushima radionuclides measured in the northern hemisphere. Sci. Total Environ. 458-460, 577-613 (2013).

4. Steinhauser, G., Brandl, A. \& Johnson, T. E. Comparison of the Chernobyl and Fukushima nuclear accidents: A review of the environmental impacts. Sci. Total Environ. 470-471, 800-817 (2014).

5. Adachi, K., Kajino, M., Zaizen, Y. \& Igarashi, Y. Emission of spherical cesium-bearing particles from an early stage of the Fukushima nuclear accident. Sci. Rep. 3, doi: 10.1038/srep02554 (2013).

6. Stohl, A. et al. Xenon-133 and caesium-137 releases into the atmosphere from the Fukushima Dai-ichi nuclear power plant: determination of the source term, atmospheric dispersion, and deposition. Atmos. Chem. Phys. 12, 2313-2343 (2012).

7. Nagai, H., Katata, G., Terada, H. \& Chino, M. Source Term Estimation of ${ }^{131}$ I and ${ }^{137}$ Cs Discharged from the Fukushima Daiichi Nuclear Power Plant into the Atmosphere in Radiation Monitoring and Dose Estimation of the Fukushima Nuclear Accident (ed. Takahashi, S.) 155-173 (Springer Japan, 2014).

8. Katata, G. et al. Detailed source term estimation of the atmospheric release for the Fukushima Daiichi Nuclear Power Station accident by coupling simulations of an atmospheric dispersion model with an improved deposition scheme and oceanic dispersion model. Atmos. Chem. Phys. 15, 1029-1070 (2015).

9. Mizuno, T. \& Kubo, H. Overview of active cesium contamination of freshwater fish in Fukushima and Eastern Japan. Sci. Rep. 3, (2013), doi: 10.1038/srep01742.

10. Leelőssy, Á., Mészáros, R. \& Lagzi, I. Short and long term dispersion patterns of radionuclides in the atmosphere around the Fukushima Nuclear Power Plant. J. Environ. Radioact. 102, 1117-1121 (2011).

11. Leon, J. D. et al. Arrival time and magnitude of airborne fission products from the Fukushima, Japan, reactor incident as measured in Seattle, WA, USA. J. Environ. Radioact. 102, 1032-1038 (2011).

12. Hu, X.-M., Fuentes, J. D. \& Zhang, F. Downward transport and modification of tropospheric ozone through moist convection. JAtmos Chem 65, 13-35 (2010).

13. Miley, H. S. et al. Measurement of Fukushima aerosol debris in Sequim and Richland, WA and Ketchikan, AK. J Radioanal Nucl Chem 296, 877-882 (2012).

14. Christoudias, T. \& Lelieveld, J. Modelling the global atmospheric transport and deposition of radionuclides from the Fukushima Dai-ichi nuclear accident. Atmos. Chem. Phys. 13, 1425-1438 (2013).

15. Kitto, M. E. et al. Airborne gamma-ray emitters from Fukushima detected in New York State. J Radioanal Nucl Chem 296, 49-56 (2012).

16. Pittauerová, D., Hettwig, B. \& Fischer, H. W. Fukushima fallout in Northwest German environmental media. J. Environ. Radioact. 102, 877-880 (2011).

17. Masson, O. et al. Tracking of Airborne Radionuclides from the Damaged Fukushima Dai-Ichi Nuclear Reactors by European Networks. Environ. Sci. Technol. 45, 7670-7677 (2011).

18. Leppänen, A.-P., Mattila, A., Kettunen, M. \& Kontro, R. Artificial radionuclides in surface air in Finland following the Fukushima Dai-ichi nuclear power plant accident. J. Environ. Radioact. 126, 273-283 (2013).

19. Kim, C.-K. et al. Radiological impact in Korea following the Fukushima nuclear accident. J. Environ. Radioact. 111, $70-82$ (2012).

20. Huh, C.-A., Hsu, S.-C. \& Lin, C.-Y. Fukushima-derived fission nuclides monitored around Taiwan: Free tropospheric versus boundary layer transport. Earth Planet. Sci. Lett. 319-320, 9-14 (2012).

21. Shi, E. et al. Radioactive impact of the Fukushima nuclear accident on Shenyang in the northeast of China. J. Radiol. Prot. 34, 223 (2014).

22. Biegalski, S. R. et al. Analysis of data from sensitive U.S. monitoring stations for the Fukushima Dai-ichi nuclear reactor accident. J. Environ. Radioact. 114, 15-21 (2012). 
23. Paatero, J. et al. Airborne fission products in the high Arctic after the Fukushima nuclear accident. J. Environ. Radioact. 114, 41-47 (2012).

24. Povinec, P. P. et al. Fukushima-derived radionuclides in ground-level air of Central Europe: a comparison with simulated forward and backward trajectories. J Radioanal Nucl Chem 295, 1171-1176 (2013).

25. MacMullin, S. et al. Measurement of airborne fission products in Chapel Hill, NC, USA from the Fukushima Dai-ichi reactor accident. J. Environ. Radioact. 112, 165-170 (2012).

26. Nikolic, J., Pantelic, G., Todorovic, D., Jankovic, M. \& Savkovic, M. E. Monitoring of Aerosol and Fallout Radioactivity in Belgrade After the Fukushima Reactors Accident. Water Air Soil Pollut. 223, 4823-4829 (2012).

27. Lujanienè, G., Byčenkienè, S., Povinec, P. P. \& Gera, M. Radionuclides from the Fukushima accident in the air over Lithuania: measurement and modelling approaches. J. Environ. Radioact. 114, 71-80 (2012).

28. Bihari, Á. et al. Fission products from the damaged Fukushima reactor observed in Hungary. Isot. Environ. Health Stud. 50, 94-102 (2014).

29. Bossew, P. et al. Radioactivity from Fukushima Dai-ichi in air over Europe; part 1: spatio-temporal analysis. J. Environ. Radioact. 114, 22-34 (2012).

30. Cosma, C., Iurian, A. R., Niţă, D. C., Begy, R. \& Cîndea, C. Indicators of the Fukushima radioactive release in NW Romania. J. Environ. Radioact. 114, 94-99 (2012).

31. Gudelis, A. et al. Activity measurement of gamma-ray emitters in aerosol filters exposed in Lithuania, in March-April 2011. Appl. Radiat. Isot. 81, 362-365 (2013).

32. Baeza, A. et al. Influence of the Fukushima Dai-ichi nuclear accident on Spanish environmental radioactivity levels. J. Environ. Radioact. 114, 138-145 (2012).

33. Barsanti, M. et al. Environmental radioactivity analyses in Italy following the Fukushima Dai-ichi nuclear accident. J. Environ. Radioact. 114, 126-130 (2012).

34. Carvalho, F. P., Reis, M. C., Oliveira, J. M., Malta, M. \& Silva, L. Radioactivity from Fukushima nuclear accident detected in Lisbon, Portugal. J. Environ. Radioact. 114, 152-156 (2012).

35. Clemenza, M., Fiorini, E., Previtali, E. \& Sala, E. Measurement of airborne ${ }^{131}$ I, $134 \mathrm{Cs}$ and ${ }^{137} \mathrm{Cs}$ due to the Fukushima reactor incident in Milan (Italy). J. Environ. Radioact. 114, 113-118 (2012).

36. de Vismes Ott, A., Gurriaran, R., Cagnat, X. \& Masson, O. Fission product activity ratios measured at trace level over France during the Fukushima accident. J. Environ. Radioact. 125, 6-16 (2013).

37. Glavič-Cindro, D., Benedik, L., Kožar Logar, J., Vodenik, B. \& Zorko, B. Detection of Fukushima plume within regular Slovenian environmental radioactivity surveillance. Appl. Radiat. Isot. 81, 374-378 (2013).

38. Kritidis, P. et al. Radioactive pollution in Athens, Greece due to the Fukushima nuclear accident. J. Environ. Radioact. 114, 100-104 (2012).

39. Lozano, R. L. et al. Radioactive impact of Fukushima accident on the Iberian Peninsula: Evolution and plume previous pathway. Environ. Int. 37, 1259-1264 (2011).

40. Manolopoulou, M., Vagena, E., Stoulos, S., Ioannidou, A. \& Papastefanou, C. Radioiodine and radiocesium in Thessaloniki, Northern Greece due to the Fukushima nuclear accident. J. Environ. Radioact. 102, 796-797 (2011).

41. Mietelski, J. W. et al. Long-range transport of gaseous ${ }^{131} \mathrm{I}$ and other radionuclides from Fukushima accident to Southern Poland. Atmos. Environ. 91, 137-145 (2014).

42. Pham, M. K. et al. Detection of Fukushima Daiichi nuclear power plant accident radioactive traces in Monaco. J. Environ. Radioact. 114, 131-137 (2012).

43. Piñero García, F. \& Ferro García, M. A. Traces of fission products in southeast Spain after the Fukushima nuclear accident. J. Environ. Radioact. 114, 146-151 (2012).

44. Tositti, L., Brattich, E., Cinelli, G., Previti, A. \& Mostacci, D. Comparison of radioactivity data measured in PM10 aerosol samples at two elevated stations in northern Italy during the Fukushima event. J. Environ. Radioact. 114, 105-112 (2012).

45. Rizzo, S. \& Tomarchio, E. Radionuclide Concentrations in Air Particulate at Palermo (italy) Following Fukushima Accident. Radiat Prot Dosimetry ncs120. doi: 10.1093/rpd/ncs120. (2012).

46. Ioannidou, A., Manenti, S., Gini, L. \& Groppi, F. Fukushima fallout at Milano, Italy. J. Environ. Radioact. 114, 119-125 (2012).

47. Evrard, O. et al. Evidence of the radioactive fallout in France due to the Fukushima nuclear accident. J. Environ. Radioact. 114, 54-60 (2012).

48. Loaiza, P. et al. Air radioactivity levels following the Fukushima reactor accident measured at the Laboratoire Souterrain de Modane, France. J. Environ. Radioact. 114, 66-70 (2012).

49. Parache, V. et al. Transfer of ${ }^{131}$ I from Fukushima to the Vegetation and Milk in France. Environ. Sci. Technol. 45, 9998-10003 (2011).

50. Long, N. Q. et al. Atmospheric radionuclides from the Fukushima Dai-ichi nuclear reactor accident observed in Vietnam. J. Environ. Radioact. 111, 53-58 (2012).

51. Stohl, A., Forster, C., Frank, A., Seibert, P. \& Wotawa, G. Technical note: The Lagrangian particle dispersion model FLEXPART version 6.2. Atmospheric Chemistry and Physics 5, 2461-2474 (2005).

52. Draxler, R. R. \& Rolph, G. D. Evaluation of the Transfer Coefficient Matrix (TCM) approach to model the atmospheric radionuclide air concentrations from Fukushima. J. Geophys. Res. 117, D05107 (2012).

53. Hong, G. H. et al. Radioactive impact in South Korea from the damaged nuclear reactors in Fukushima: evidence of long and short range transport. J. Radiol. Prot. 32, 397 (2012).

54. Liu, L. et al. Monitoring of atmospheric radionuclides from the Fukushima nuclear accident and assessing their impact on Xi'an, China. Chin. Sci. Bull. 58, 1585-1591 (2013).

55. Momoshima, N., Sugihara, S., Ichikawa, R. \& Yokoyama, H. Atmospheric radionuclides transported to Fukuoka, Japan remote from the Fukushima Dai-ichi nuclear power complex following the nuclear accident. J. Environ. Radioact. 111, 28-32 (2012).

56. Hu, X.-M., Doughty, D. C., Sanchez, K. J., Joseph, E. \& Fuentes, J. D. Ozone variability in the atmospheric boundary layer in Maryland and its implications for vertical transport model. Atmos. Environ. 46, 354-364 (2012).

57. Hastings, D. A. \& Dunbar, P. K. Global land one-kilometer base elevation (GLOBE) digital elevation model, documentation. Key to Geophysical Records Documentation (KGRD) 34, 1999 (1999).

58. Moreira, V., Degrazia, G. A., Robertia, D. R., Timm, A. U. \& da Costa Carvalho, J. Employing a Lagrangian stochastic dispersion model and classical diffusion experiments to evaluate two turbulence parameterization schemes. Atmos. Pollut. Res. doi: 10.5094/ APR.2011.043. (2011).

59. Leadbetter, S. J., Hort, M. C., Jones, A. R., Webster, H. N. \& Draxler, R. R. Sensitivity of the modelled deposition of Caesium-137 from the Fukushima Dai-ichi nuclear power plant to the wet deposition parameterisation in NAME. J. Environ. Radioact. 139, 200-211 (2015).

60. Hunter, J. D. Matplotlib: A 2D Graphics Environment. Comput. Sci. Eng. 9, 90-95 (2007).

\section{Acknowledgements}

This work was supported by the National Research, Development and Innovation Office of Hungary (No. K104666, No. K109109 and No. K116506). 


\section{Author Contributions}

R.M., T.K. and I.L. designed the research. A.L. performed numerical simulations and data analysis. R.M., A.L., T.K. and I.L. interpreted the data and wrote the manuscript.

\section{Additional Information}

Supplementary information accompanies this paper at http://www.nature.com/srep

Competing financial interests: The authors declare no competing financial interests.

How to cite this article: Mészáros, R. et al. Predictability of the dispersion of Fukushima-derived radionuclides and their homogenization in the atmosphere. Sci. Rep. 6, 19915; doi: 10.1038/srep19915 (2016).

(c) (i) This work is licensed under a Creative Commons Attribution 4.0 International License. The images or other third party material in this article are included in the article's Creative Commons license, unless indicated otherwise in the credit line; if the material is not included under the Creative Commons license, users will need to obtain permission from the license holder to reproduce the material. To view a copy of this license, visit http://creativecommons.org/licenses/by/4.0/ 